\title{
O Brasil, os imigrantes italianos e a política externa fascista, 1922-1943
}

\author{
JOÃO FÁBIO BERTONHA*
}

Desde o fim da Segunda Guerra Mundial, número substancial de historiadores e estudiosos italianos se dedicaram ao tema da política externa fascista. As origens do imperialismo fascista, a questão da continuidade ou da ruptura entre a política externa fascista e a da Itália unida, o realismo e o papel da ideologia nessa política e outros pontos foram esmiuçados a fundo, gerando um imenso volume de bibliografia sobre o tema ${ }^{1}$.

Como seria de se esperar, a esmagadora maioria desses trabalhos envolve a área geográfica tradicional da política externa italiana, ou seja, a Europa. Às outras áreas de atuação da política externa do regime de Mussolini era dedicado, até recentemente, pouco ou nenhum esforço de análise, criando uma lacuna que só nos últimos anos - e em boa parte por mérito dos historiadores agrupados em torno da revista Storia Contemporanea (QUARATO, 1987) - começou a ser fechada graças a diversos trabalhos sobre a atuação da diplomacia fascista no Oriente Médio, China, Japão etc. ${ }^{2}$.

Pouco se fez, porém, com relação a uma área geográfica que, mesmo sendo, sem dúvida, menos importante para a política externa fascista que a Europa ou os Estados Unidos, nos parece muito mais relevante para a Itália (dada a afinidade latina e a presença maciça de imigrantes italianos) que, por exemplo, o Japão e a China: a América Latina ${ }^{3}$. Claro que trabalhos abordando indireta ou parcialmente o tema surgiram nos últimos anos mas, com exceção do interessante texto de Marco Mugnaini (MUGNAINI, 1986), o autor desconhece a existência de trabalhos que aprofundem a questão. O presente texto visa fornecer subsídios para a superação dessa lacuna através da abordagem do caso brasileiro e da compreensão dos objetivos fascistas dentro do relacionamento Brasil-Itália e da política migratória.

* Doutorando em História da Universidade de Campinas. 


\section{As relações Brasil-Itália no período pré-fascista ${ }^{4}$}

As relações bilaterais entre o Reino da Itália e o Brasil foram geralmente marcadas pela amizade e simpatia (SEITENFUS, 1985, cap. 3), com os governos italiano e brasileiro tendo normalmente uma imagem positiva um do outro. Desde 1870, mecanismos para entendimento mútuo foram criados e os organismos diplomáticos de ambos os países nunca perderam o contato entre si.

No início desse relacionamento, o governo brasileiro tomava mais regularmente as iniciativas, sempre em busca de mercados e trabalhadores que mantivessem funcionando a grande estrutura econômica do país no período, ou seja, a lavoura do café.

A situação se alterou a partir dos anos 80 do século XIX, quando uma torrente de imigrantes italianos se estabeleceu no sul e sudeste do Brasil. Os homens de Estado italianos passaram, então, a se interessar mais pela situação do gigante sul-americano, mas tendo em vista basicamente duas linhas de ação: a proteção dos conacionais e a promoção do comércio e das relações econômicas.

Em relação ao segundo ponto, as esperanças do governo de Roma de que a maciça presença de imigrantes italianos no Brasil geraria uma enorme demanda por produtos italianos não se verificou pela ausência de acordos alfandegários liberalizando o comércio entre os dois países, ineficiência do sistema de comunicações e transportes e especialmente porque os ítalo-brasileiros foram pródigos em criar uma produção agrícola e industrial própria para atender essa demanda (TRENTO, 1989, p. 68-74).

Já a proteção e a tutela dos imigrantes e a tentativa de mantê-los ligados à Itália eram comuns à política italiana de então, mas foram de difícil aplicação no Brasil devido à pouca resistência dos italianos ao processo de assimilação e à escassa disponibilidade de meios à disposição do governo italiano para tentar detêlo. Ainda assim, atritos entre os governos brasileiro e italiano por causa dos prejuízos econômicos sofridos pelos italianos nas guerras e revoluções internas no Brasil e pela superexploração dos colonos foram uma constante, apesar de não abalarem o clima geralmente cordial entre Roma e o Rio de Janeiro.

Apenas em fins do século XIX esse clima amistoso foi realmente ameaçado quando conflitos de rua entre italianos e brasileiros em São Paulo causaram um estremecimento das relações entre os dois países, com o governo italiano levantando até a possibilidade de enviar uma expedição naval contra o Brasil (GABRIELE, 1967). Foram, porém, fatos isolados e, à parte vozes solitárias na Itália que pretendiam algum tipo de atitude colonialista em relação ao Brasil ${ }^{5}$, a atitude e as pretensões italianas em relação ao país sempre foram bastante modestas, o que permitiu que a transfusão de população entre os dois países se desse sem que - ao contrário do caso alemão ${ }^{6}$ - preocupações de um "perigo italiano" à soberania e à independência brasileira estivessem presentes ${ }^{7}$. 


\section{O Brasil e a política externa fascista}

Como já apresentado, o interesse historiográfico pelas relações entre a Itália fascista e o Brasil é incipiente e, apesar da existência de alguns textos que abordam a questão com alguma profundidade (MUGNAINI, 1986; CERVO, 1990 e 1992; SEITENFUS, 1985 e 1990), a produção historiográfica não conseguiu ainda sair de algumas conclusões genéricas e certamente corretas mas que precisam ser tanto melhor verificadas empiricamente como receber um recorte temporal mais preciso.

De fato, a bibliografia disponível insiste em ressaltar as boas relações governo a governo, a falta de um real conflito de interesses entre a Itália e o Brasil por causa do destino da coletividade italiana presente no Brasil, a boa imagem desfrutada por cada povo em relação ao outro, a (em geral) improvisação e falta de objetivos definidos por parte de Roma etc. Nada parece indicar que essas conclusões gerais mereçam substancial revisão, mas um estudo mais detalhado dos interesses do governo fascista em relação ao Brasil parece ser fundamental para aprofundar essas conclusões e delimitar melhor a teia de objetivos políticos que norteava o relacionamento entre os dois países.

Do mesmo modo, é historicamente incorreto tratar o período de 1922 a 1942 como um todo único e sempre igual. Os autores citados obviamente não são tão ingênuos a ponto de cometer esse erro grosseiro. Ainda assim, é fundamental um melhor cuidado para estabelecer as alterações de diretrizes e políticas que marcaram as políticas externas brasileira e italiana (e, portanto, o relacionamento entre os dois países) no período.

De fato, não só a política externa brasileira vai passar por diferentes fases naqueles anos (CERVO, 1992a) como, o que é mais importante para nossos objetivos de delimitar os interesses do governo fascista no Brasil, a própria política externa italiana não será a mesma em todo o ventênio fascista.

Não é esse certamente o lugar para retomar o intenso debate da historiografia italiana sobre a evolução da política externa fascista, suas diferentes fases etc. É ponto passivo para o autor, porém, que a política externa do regime fascista não foi - dada a evolução ideológica do regime e seu consolidamento interno, as mutantes condições do sistema internacional etc - a mesma nos seus 20 anos de existência e que uma análise dos interesses italianos no Brasil e do próprio relacionamento Brasil/Itália no período deve levar em conta os padrões variáveis dessa política. É nesse sentido que temos que fazer recortes temporais precisos dentro do espaço de 20 anos em que o regime de Mussolini dedicou interesse à nação brasileira. 


\section{Os anos 20}

No decorrer dos anos 20, o regime fascista recuperou a antiga idéia de criar uma Itália no exterior via emigração (ainda que sob um novo enfoque) e o seu objetivo de expandir as fronteiras econômicas e culturais italianas através da mesma. Essa política - que dura, grosso modo, até o final da década de 20 - se refletiu nos interesses italianos no Brasil. De fato, em vez de ver no país mera válvula de escape para a exuberância demográfica italiana, o governo fascista passou a ver, no Brasil, um terreno fértil onde se podiam perseguir objetivos econômicos, culturais e mesmo políticos (CERVO, 1990, p. 28 e SEITENFUS, 1984).

Isso não quer dizer, claro, que o governo italiano não mantivesse um grande interesse (ainda mais levando-se em conta que as portas para a emigração italiana nos Estados Unidos iam se fechando e a política de não-emigração fascista ainda não havia se iniciado) em usar o Brasil para absorver o excedente demográfico italiano ${ }^{8}$. Tanto que várias tentativas de acordos de colonização foram feitos, os quais só não levaram aos resultados desejados devido às péssimas condições de trabalho nas fazendas paulistas, as quais afastaram do Brasil a emigração italiana daqueles anos (TRENTO, 1989, p. 267-281; OSTUNI, 1983).

Os interesses italianos em ampliar o comércio e o relacionamento econômico entre Brasil e Itália, em tutelar os seus emigrantes e em realizar uma política de difusão cultural também estão ainda muito próximos dos padrões das políticas anteriores, mas tais esforços passaram a ser potencializados - reativando a Câmara de Comércio italiana em São Paulo ${ }^{9}$, enviando a missão Giuriati à América Latina para ampliar o intercâmbio econômico ${ }^{10}$, redobrando os esforços para ligar os imigrantes e seus descendentes à Itália, etc - e, especialmente, passou-se a ter um quadro mais preciso do papel que os emigrantes e sua tutela teriam dentro do interesse italiano em desfrutar os recursos econômicos do Brasil.

Os anos 20 vão ver, de fato, uma profusão de declarações dos representantes italianos no Brasil $^{11} \mathrm{e}$ de pensadores da própria Itália ${ }^{12}$ sobre como a espansão italiana no mundo se daria pela via econômica e cultural e como, nesse contexto, o Brasil - e especialmente São Paulo - seria um lugar privilegiado, onde surgiria uma grande nação latina ligada culturalmente à Itália ${ }^{13}$ e um mercado capaz de absorver imensas quantidades de produtos italianos e complementar a sua economia com vasto fornecimento de minérios, matérias primas e alimentos.

Nesse quadro, não só a reabertura da emigração italiana para o Brasil era usada, sem maiores escrúpulos, como instrumento de chantagem para a obtenção de vantagens comerciais (TRENTO, 1989, p. 277-278) como a própria comunidade italiana já instalada no país seria chave ao gerar os mercados para os produtos italianos e para criar uma influência cultural que se transmutaria em um relacionamento mais próximo e harmonioso entre os dois países (CAMERA, 1924 e 1927). 
Dentro desses objetivos, era fundamental a conservação dos laços da coletividade italiana com a Pátria mãe e a preservação do sentimento de italianidade entre as novas gerações (MANCINI, 1924), o que ajuda a explicar, ao lado de questões relativas à própria ideologia fascista, o fervor com que o governo italiano procurou reativar os laços de suas coletividades na América Latina com a Itália.

Os interesses italianos para o Brasil nos anos 20 podem ser melhor compreendidos, porém, através da leitura de um surpreendente relatório escrito em 1925 por um emissário do governo italiano que, após passar três anos no Brasil, enviou um relato incrivelmente lúcido, tanto sobre a situação dos italianos no Brasil como sobre as pretensões de Roma no país na década de 20.

Umberto Sala inicia seu relatório ${ }^{14}$ comentando como a Itália continuava sua crise demográfica e que, fechada a porta americana, a única saída disponível era a América do Sul e, em especial, o Brasil. Sala ressaltava imediatamente, porém, que isso era apenas um potencial e que vários fatores (exploração capitalista em níveis fora do concebível mesmo de italianos para italianos, ação estatal de proteção aos trabalhadores inexistente, etc) inibiam um retorno da migração italiana de massa para o Brasil.

Ainda assim, o autor acreditava no enorme potencial do Brasil e em especial do Estado de São Paulo e augurava como fundamental o não abandono do país pela política italiana.

Nesse sentido, Umberto Sala lamentava o relativamente baixo nível de envolvimento dos italianos na política paulista e discutia como seria proveitoso fazer os italianos e seus filhos conservarem a italianidade, mas agirem na política local em defesa dos interesses da comunidade e da Pátria mãe. Nesse momento, o autor ressaltava que, se fosse possível realmente fazer os italianos influírem na vida política do Estado, estes conseguiriam, por simples peso demográfico, criar um grande centro de influência italiana na América Latina.

Incorporar militarmente esse centro à Itália seria, continua o autor, muito difícil devido à distância e à presença do poder dos Estados Unidos, mas surgiria, de qualquer forma, um centro de expansão da raça italiana, onde a solidariedade de origem, raça e cultura formaria algo semelhante a um "Dominion" inglês como o Canadá ou a Austrália, onde se poderia contar com um lugar conveniente para enviar os excedentes demográficos italianos, um aliado seguro em caso de guerra e uma complementação econômica que seriam básicas para a sobrevivência da raça italiana. A tendência separatista de São Paulo também seria um fator auxiliar para firmar o predomínio italiano no estado.

Em nome dessas possibilidades, o autor recomendava o retorno da imigração italiana, as boas relações com o Brasil e a firme união da coletividade em torno da italianidade e das diretrizes de Roma. Para isso, as sessões dos fasci all'estero e das associações dos ex-combatentes seriam fundamentais, e ele termina seu relatório ressaltando o progresso e o desenvolvimento desses órgãos, 
fundamentais para fazer a colônia cerrar fileiras em torno das diretrizes e interesses fascistas.

Vê-se, assim, que, se é verdade que as relações ítalo-brasileiras nos anos 20 se centraram basicamente nas questões da imigração e do relacionamento comercial (SEITENFUS, 1990) e que mesmo estas terminaram com baixo sucesso italiano em suas pretensões ${ }^{15}$, outros interesses, como a influência política direta, não estavam fora de cogitação, só deixando de ser implementados não por uma especial delicadeza fascista em relação ao Brasil, mas pela consolidação do regime e o amadurecer das suas, sempre presentes, tendências imperialistas (no sentido mais clássico do termo) ainda estarem se processando; pela concentração dos interesses italianos, nesse momento, na Europa e no Mediterrâneo e pela consciência de que a fraqueza militar italiana, a presença dos EUA como potência hegemônica no continente americano e o contexto internacional não abriam à Itália nenhuma perspectiva de sucesso nesse campo.

Mesmo assim, é manifesto que, apesar dos alertas dos antifascistas italianos sobre a ameaça do imperialismo fascista sobre o Brasil (BERTONHA, 1996, p. 42-44) e de dúvidas que a imprensa brasileira levantava na época sobre as possibilidades do expansionismo fascista se dirigir ao Brasil, as pretensões fascistas nunca foram - dadas as razões mencionadas - muito ambiciosas, e que comércio e manutenção da italianidade dos imigrantes eram realmente as questões-chave dos interesses italianos nos anos 20. A situação começaria a mudar logo em seguida.

\section{Os Anos 30}

Como explicitado anteriormente, não é este o espaço para discutir a ampla literatura disponível sobre os caminhos e a evolução da política externa italiana durante o fascismo. É importante observar, porém, que os anos 30 vêem o regime fascista aprofundar suas sempre existentes tendências imperialistas e totalitárias e refinar a idéia de um verdadeiro "Império italiano" no mundo. Tal transformação não podia deixar de ter reflexos na política e nos interesses italianos em relação ao Brasil.

Marco Mugnaini (MUGNAINI, 1986) nos dá um excelente resumo sobre as novas pretensões do governo italiano na América Latina e no Brasil (superando a política anterior, centrada na questão dos emigrantes e do comércio) a partir, grosso modo, do início da década de 30. Dentre essas pretensões, destacam-se o combate aos grupos antifascistas italianos locais, a busca de um apoio político às pretensões mediterrâneas/européias do regime e a ampliação da influência política, econômica e cultural da Itália na região.

Parece óbvio que essa política não era isenta de incoerências e hesitações (ALBONICO, 1982), que Mussolini sabia dos limites do seu “jogo" latino-americano (dada a presença hegemônica dos EUA) e que a América Latina continuava 
secundária nos planos expansionistas do regime. Ainda assim, era uma fase diferente da política italiana para a América Latina que se iniciava.

A documentação de época confirma esses sinais da ampliação dos interesses italianos em relação à América Latina em geral ${ }^{16} \mathrm{e}$ também ao Brasil. Em 1931, por exemplo, o Ministero degli Affari Esteri chegou a discutir a possibilidade de apoiar o separatismo dos estados do Sul do Brasil para conseguir influência redobrada nessa nova federação, que concentraria a esmagadora maioria da comunidade italiana instalada no país ${ }^{17}$.

O exemplo mais claro da nova orientação da política italiana para o Brasil nesse momento (em busca de real influência política), porém, é o relatório reservado que a Embaixada italiana enviou ao Ministero degli Affari Esteri em 11/4/1933 e do qual convém fazer uma longa citação:

"Não parece que, até agora, a Itália tenha tentado, em linhas gerais, influir no Brasil: o país é submetido, de fato, a tal ação direta da diplomacia norte-americana, que verdadeiramente não se pode pensar em mudar o estado das coisas. Acrescente-se a isto o fato, lamentável mas indiscutível, que os dois milhões de assim chamados italianos que aqui vivem e trabalham, no interesse único do Brasil, não têm nenhuma influência na política interna do país, ao qual estes trouxeram, todavia, riqueza, prestígio e civilização. Não excluo que, se não tivéssemos no Brasil uma emigração que sempre se desnacionaliza mais, poderíamos talvez exercitar uma ascendência maior, mas as nossas colônias aqui estabelecidas constituem-se num peso morto mesmo para a nossa ação geral no país. Amarga realidade, que nenhum italiano verdadeiramente novo tem mais o direito de esconder.

Outro motivo que pode ter induzido a nossa diplomacia a omitirse de influir nas classes dirigentes e sobre a opinião pública do país em favor da política italiana foi certamente a consideração desencorajadora que o Brasil na Europa não conta. Não me parece, todavia, que esta seja uma razão suficiente para aceitarmos que a itália, por sua vez, não conte nada no Brasil. São duas concepções em eterna polêmica: cultivar ou ignorar os países secundários? Eu subordinadamente me solidarizo há muito com os que sustentam a tese ativa, favorável à exploração de qualquer vantagem, mesmo modesta, que se possa obter a favor dos nossos interesses, e as experiências diplomáticas do autor confirmam a opinião de que se pode obter alguma coisa mesmo dos mais pequenos e que em todos os casos o favor, ainda que platônico, da maioria , deve ser cultivado. Além disso, a disputa pela opinião pública do país pelas 
diversas Embaixadas é notável e não vejo porque deveríamos ficar ausentes." 18

É curioso notar que esse renovado interesse italiano pelo Brasil se dá num momento em que os interesses econômicos italianos no país (dada a permanência de relações comerciais apenas incipientes e a contínua assimilação da colônia italiana) vão diminuindo ${ }^{19}$, o que revela que são realmente os sonhos fascistas da construção do Império e de um sólido prestígio internacional para a Itália (centrados, obviamente, na Europa e na zona mediterrânea, mas que podiam ser levados a cabo, se houvesse possibilidade e oportunidade, em outros locais ${ }^{20}$ ), que explicam o renovado esforço fascista em influenciar os rumos políticos do Brasil.

É claro que essa nova tendência do governo fascista em seu relacionamento com a América Latina não se devia apenas à evolução do regime com relação à política emigratória, o expansionismo em todas os locais onde houvesse oportunidade etc. Também foi importante, para essa mudança, a ascensão de diversas ditaduras militares na América do Sul no início dos anos 30, que alçou as esperanças de maior influência por parte de Roma, a qual identificava nesses governos autoritários clientes em potencial do fascismo.

Como bem ressalta Marco Mugnaini (MUGNAINI, 1986, p. 208-211), as esperanças de Roma se frustraram um pouco devido ao nacionalismo desses regimes - que entravam em conflito com a renovada política italiana de tentar impedir a absorção de suas coletividades no exterior - mas as relações com os governos Vargas no Brasil, Uriburu na Argentina e outros se mantiveram cordiais e continuariam assim durante os anos 30 .

Mais importante que tudo nesse momento, porém, é identificar uma tendência dentro da política externa fascista que esteve presente desde os anos 20 mas que adquiriu mais força e visibilidade nos anos 30: a fusão dos objetivos nacionais do Estado italiano com aqueles de divulgação e expansão da ideologia fascista.

Dentro dessa tendência, interesses nacionais italianos e ideologia fascista se fundiam num todo muitas vezes contraditório e ambíguo, mas que passa a condicionar cada vez mais a política externa italiana a partir de então: os interesses do Estado italiano podiam ser atingidos através da carta ideológica, de solidariedade dos regimes de caráter fascista e a própria expansão da ideologia fascista se daria pelos mecanismos de poder do Estado italiano.

Dentro desse contexto é que podemos entender as esperanças do governo de Mussolini com os regimes autoritários que surgiram na América do Sul no início dos anos 30. Estes regimes, porém, não deram à Itália (apesar de sua simpatia pelo fascismo) a influência que ela almejava na região.

O surgimento de grupos de clara tendência fascista na América Latina a partir de 1932/33 abriu, contudo, um novo canal pelo qual a influência italiana 
podia ser transmitida. No caso brasileiro, essa possibilidade foi explorada a fundo através do mais importante movimento fascista das Américas: A Ação Integralista Brasileira (AIB).

\section{A carta ideológica (1935-1938)}

Como visto, a idéia fascista de influenciar politicamente o Brasil se desenvolveu e se consolidou no decorrer dos anos 30. Nesse período também, como já explicitado, o governo fascista acreditava ter encontrado uma maneira de superar as deficiências em poder econômico e militar que haviam prejudicado os esforços italianos no passado: a criação de uma ponte ideológica entre os dois países, que serviria para compensar quaisquer debilidades italianas para sustentar seus esforços hegemônicos no país. A expansão ideológica do fascismo seria a grande arma de ação da Itália no Brasil e na América Latina em geral (TOSCANO, 1980).

Como vimos, essa experiência começou no início dos anos 30, com os regimes militares que começaram a assumir o poder em diversas partes do subcontinente mas só se solidificou quando o fascismo a refinou (SANTARELLI, 1981) e, principalmente, passou a contar com interlocutores adequados nos países latino-americanos. No caso do Brasil esse interlocutor foi, sem dúvida, o Integralismo.

Antes, porém, de entrarmos no complexo relacionamento entre fascistas e integralistas, convém fazer uma pausa para discutir os objetivos dessa nova fase da política italiana para a América Latina e o Brasil. Até onde chegariam as novas pretensões e desejos do regime fascista?

Durante os anos 30, a perspectiva de uma invasão nazista com o apoio da aparentemente $100 \%$ nazistificada coletividade alemã do Sul do país preocupou enormemente círculos políticos e militares no Brasil e nos Estados Unidos ${ }^{21}$. Raramente, porém, essa possibilidade foi levantada com relação aos italianos ${ }^{22}$.

Essa confiança na Itália derivava certamente da maior simpatia de setores da sociedade brasileira pela Itália e pelo fascismo italiano que por seus congêneres alemães, mas também da evidente incapacidade italiana em sustentar uma invasão armada contra o Brasil, incapacidade esta que fez com que projetos de invasão nunca estivessem entre os planos do governo italiano (BOREJSZA, 1971, p. 147).

Descartada essa hipótese, o grande objetivo do governo italiano passou a ser - descontada a continuidade de interesses econômicos e de manutenção da italianidade da colônia italiana - a quebra da hegemonia americana e a formação de um grande bloco de nações latinas e fascistas ligadas a Roma ${ }^{23}$.

Parece evidente que esse interesse da Itália fascista por uma hegemonia política no Brasil era bastante teórico e condicionado pelas prioridades e pelos 
recursos italianos (tanto que, como vimos, a ameaça italiana nunca foi levada tão a sério, por brasileiros e americanos, como a alemã). O fato, porém, é que essa pretensão existia e, para atendê-la, o governo italiano dispunha, no Brasil, de um tripé formado por três pólos: a coletividade italiana, a propaganda direta e o seu intenso relacionamento com o fascismo brasileiro representado pelo Integralismo e, em menor escala, com o regime do Estado Novo de Getúlio Vargas.

Esses três pontos serão objeto de discussão mais aprofundada em textos futuros do autor. Por ora, basta identificar alguns aspectos desse triângulo e como eles se relacionavam com os ideais hegemônicos italianos.

O primeiro instrumento de ação italiana era a propaganda direta da ideologia fascista entre a opinião pública brasileira. Essa propaganda foi mais característica a partir da segunda metade da década de 30 e foi tão marcante que merecerá uma análise bem mais aprofundada em textos posteriores. Por ora e para os objetivos desse artigo, o que é necessário saber é para que servia, dentro dos interesses italianos, esse esforço de propaganda da Itália.

Mario Toscano (TOSCANO, 1980, p. 247) vai propor que a propaganda italiana era muito genérica e que visava mais uma difusão do fascismo e a fabricação de uma imagem positiva para ele no país que realmente uma busca de influência direta.

Essa posição de Toscano merece ser relativizada. De um lado, é uma realidade que o fascismo procurava difundir sua imagem, em termos genéricos, no Brasil, também para seus fins de obtenção de um consenso externo para o regime, que sua política de propaganda foi cautelosa e muitas vezes contraditória - para evitar danos no relacionamento com o governo do Rio de Janeiro (SEITENFUS, 1990, p. 40-41) - e que encontrou enormes dificuldades em sua execução. Em última instância, porém, parece estar presente, como pano de fundo, o desejo italiano de usar a propaganda cultural e de difusão do fascismo como instrumento de penetração política capaz de influir em senso fascista e pró-Itália a política interna e externa do Brasil ${ }^{24}$.

Ao lado dessa propaganda direta, um outro instrumento de penetração fascista nessa nova fase seria a imensa coletividade italiana, a qual deveria continuar a ter um papel chave na aplicação dos interesses italianos no Brasil, mas com objetivos e diretrizes mais realistas.

De fato, se, nos anos 20, a coletividade italiana deveria ser usada basicamente como consumidora de produtos italianos e para auxiliar na influência indireta da Itália no país, as pretensões fascistas em relação à colônia mudam nos anos 30, revelando a capacidade dos agentes diplomáticos italianos em avaliar as reais possibilidades de ação italiana no país via comunidade italiana.

Que o Ministero degli Affari Esteri tinha esperanças em usar a coletividade italiana do Brasil para influenciar a política brasileira em sentido pró-fascista é algo inegável e que pode ser comprovado por um comunicado que ele envia aos 
embaixadores da América Latina em 1937 requerendo informações sobre a força política de cada colônia e pedindo para os Embaixadores examinarem a possibilidade de as mesmas servirem para influenciar esses países ${ }^{25}$.

Num outro memorando, dirigido especificamente para o o embaixador Lojacono no Rio de Janeiro em 26/4/193726, o Ministero degli Affari Esteri revelase incrivelmente lúcido e realista, porém, sobre as reais possibilidades de uso da coletividade italiana para influenciar politicamente o Brasil. Em primeiro lugar, relembra que, dada a estrutura política brasileira, a capacidade dos italianos locais de influenciar as diretrizes políticas do governo brasileiro tinham sido sempre limitadas e que mesmo durante a Guerra da Abissínia, quando o Brasil não aderiu ao boicote da Sociedade das Nações, essa posição pró-Itália era mais uma derivação dos interesses brasileiros e da neutralidade dos Estados Unidos que efetivamente uma conquista da pressão dos italianos locais ${ }^{27}$.

Ao lado dessa consciência de que a situação das coletividades italianas nos países latino-americanos era muito particular e que não se poderia esperar muito delas em termos de fonte de pressão política (como ocorria nos EUA) ${ }^{28}$ e muito menos como uma "quinta coluna” ou força de apoio para uma possível invasão (o que se esperava, por exemplo, dos italianos da Tunísia - BESSIS, sem data), o governo italiano também demonstrava consciência das mudanças demográficas das coletividades italianas da América do Sul e que era aos filhos de italianos que o regime devia se dirigir (mantendo-os ligados à Itália) se quisesse exercer alguma influência na política latino-americana e na brasileira em particular ${ }^{29}$.

Isso, na verdade, vinha sendo inferido com cada vez mais clareza pelos orgãos diplomáticos italianos e seus representantes no Brasil desde o início dos anos 30. De fato, já em 1934, a Embaixada italiana assim se expressava ao comentar a nomeação de Vicente Rao, filho de italianos, ao posto de Ministro da Justiça do Brasil:

“ (...) é o primeiro filho de italianos que chega a um cargo como este. Se não for o único e se muitos seguirem o seu exemplo, a política dos filhos de italianos, que eu não me canso de apresentar como indispensável ao nosso país na América do Sul, dará frutos fecundos e necessários.” 30

De forma coerente, o governo fascista parece ter percebido não só que os filhos de italianos iam representando cada vez mais a maioria absoluta da colônia italiana no Brasil no decorrer dos anos 30 como que a eles não deviam ser dirigidos apelos excessivos pois, apesar de serem majoritariamente pró-fascistas e com grande admiração por Mussolini, não eram, certamente, os soldados fiéis esperados pelo Consulado ${ }^{31}$ e, no caso de terem que escolher entre o Brasil e a Itália, sem 
dúvida optariam pelo primeiro. Não era possível, assim, exigir muito da coletividade italiana do Brasil, e o regime não o fez ${ }^{32}$.

Dada essa situação, era à outra arma que o regime fascista dedicava suas esperanças para aumentar sua influência no Brasil: seu intenso relacionamento com o fascismo brasileiro, o Integralismo.

Uma apreciação dos íntimos laços que o fascismo italiano teve com a Ação Integralista Brasileira (em termos institucionais, de relações de base e de cúpula, de influência ideológica, etc) já foi feita por diversos pesquisadores ${ }^{33}$ , e o próprio autor trabalha atualmente num texto a respeito. Por ora, o mais interessante é destacar o que o governo italiano esperava, em termos de retornos geopolíticos e estratégicos, da aliança e da solidariedade ideológica com os integralistas ${ }^{34}$.

Um primeiro sinal nos é dado pelo embaixador Lojacono que, em 1937, dizia que o essencial era:

\begin{abstract}
"romper o fronte democrático no maior país da América do Sul, criar um ambiente que seja favorável, por razões de analogia, ao nosso regime, cultivar uma opinião nacional brasileira aberta às premissas e às necessidades da Itália, abrir uma fonte de consenso moral e de recursos materiais naquela parte do mundo que estará à menor distância do nosso eixo imperial e do nosso aparato respiratório, eis o que significa o estabelecimento de um estado integralista no Brasil.”35
\end{abstract}

Um outro sinal dessa ambição de Roma pode ser encontrado num relatório secreto, escrito por Cesare Rivelli, funcionário do Consulado italiano de São Paulo, gestor de várias atividades de propaganda fascista no país (sendo inclusive redator do Fanfulla) e agente de ligação do fascismo com os integralistas.

Nesse relatório, Rivelli analisa as possibilidades de o Integralismo chegar ao poder no Brasil, a conveniência em apoiá-lo e como fazê-lo e conclui que era uma aposta arriscada mas que devia ser feita, pois:
“Um Brasil integralista, obediente à vontade de Roma constituiria um magnífico ponto de partida para a hegemonia italiana nessa parte do continente, além de representar um mercado vastíssimo facilitado à nossa produção agrícola, industrial, intelectual.”36

Ao mesmo tempo, porém, que jogavam suas esperanças na Ação Integralista, os italianos sentiam-se bastante atraídos pelo governo do presidente Vargas, que não só ia, aparentemente, aplicando cada vez mais princípios fascistas à administração do Brasil como era extremamente amigo da Itália, tendo inclusive 
resistido, como visto, às pressões inglesas para aderir ao boicote anti-italiano da Sociedade das Nações em 1936. Dada essa situação, não espanta que dúvidas sobre qual caminho tomar (apoio ao Integralismo ou ao regime de Vargas) apareçam regularmente na documentação italiana. ${ }^{37}$

Na realidade, porém, o caminho mais conveniente para os italianos seria uma aliança entre Getúlio Vargas e os integralistas para uma condução segura do Brasil para os caminhos do Eixo, e há vários exemplos disponíveis sobre a esperança e o desejo fascista de que o regime de Vargas e a Ação Integralista se reunissem para empreender a tarefa de criar o Brasil fascista.

Isso pode ser confirmado, por exemplo, pelo comunicado que o Ministero degli Affari Esteri enviou à imprensa italiana em 1937 ordenando que as notícias sobre a criação do Estado Novo no Brasil mencionassem tanto Vargas quanto o Integralismo e auspiciassem sua união ${ }^{38}$. Em 1946, o ex-funcionário da Embaixada italiana Nunzio Greco também indicou, em entrevista, que a esperança fascista para afastar o Brasil do campo democrático residia num sólido bloco AIB/Vargas ${ }^{39}$, enquanto o gerarca fascista Luigi Federzoni, em entrevista ao Il Popolo d'Italia de 13/11/1937, mal consegue conter seu entusiasmo frente às duas "grandes forças renovadoras da política brasileira" e que deveriam continuar juntas para o bem do país ${ }^{40}$.

Com o tempo, torna-se visível a decepção italiana com a incapacidade integralista de tomar o poder pela força, e seu encanto com o Estado Novo varguista cresceu continuamente. Grandes discussões foram mantidas na imprensa e entre os diplomatas italianos sobre a real filiação ideológica do Estado Novo (TOSCANO, 1980) mas, por fim, a decisão italiana passou pelo abandono dos integralistas e pelo apoio ao novo regime brasileiro, que recebeu então imensa atenção por parte da propaganda italiana ${ }^{41}$.

Essa política ambígua e muitas vezes contraditória entre o Integralismo e o Estado Novo varguista demonstra como, apesar dos esforços italianos, os meandros da política brasileira ainda eram relativamente desconhecidos por Roma (o que levava a apostas dificilmente realizáveis, como a da aliança entre Getúlio Vargas e Plínio Salgado) e, especialmente, o imenso pragmatismo das atividades italianas que, mesmo se baseando numa carta ideológica como o cerne de sua política, podiam ser alteradas e reformuladas conforme a situação o exigisse.

Parecem estar claros, de qualquer forma, os objetivos da Itália em relação ao Brasil na segunda metade dos anos 30 e as armas - a propaganda direta, a coletividade italiana e, especialmente, o jogo entre a Ação Integralista e o Estado Novo - de que ela dispunha nesse jogo.

É importante notar, porém, que esses diferentes instrumentos não eram utilizados e pensados como compartimentos estanques ${ }^{42}$, mas como uma rede cuidadosamente planejada - o que não significa dizer que não havia contradições e problemas - para atender aos interesses da Itália fascista no Brasil. 
De fato, não só os italianos jogavam continuamente entre Getúlio Vargas e Plínio Salgado como a forte propaganda fascista dirigida à opinião pública brasileira e as atividades fascistas dentro da coletividade italiana ajudaram a criar um "clima" de grande utilidade tanto para os integralistas como para o regime de Vargas. Além disso, o governo italiano via, por exemplo, a entrada maciça dos filhos de italianos na Ação Integralista como uma chave para subtraí-la à influência nazista, e a própria AIB era vista como o canal privilegiado para inserir os filhos de italianos na política brasileira em um sentido pró-Itália e difundir a realidade fascista no país ${ }^{43}$. Coletividade italiana, propaganda direta e uma política de equilíbrio entre 0 governo brasileiro e os fascistas locais eram, portanto, braços conectados de uma mesma estrutura destinada a conduzir o Brasil à aproximação com o Eixo.

Nas memórias do embaixador Raffaelle Guariglia, aliás, há referências de que Mussolini havia se impressionado com a firme e positiva resposta da coletividade italiana do Brasil aos apelos da Pátria mãe durante a guerra da Abissínia (em oposição à Argentina) e acreditado na sua total devoção ao regime. Ele também teria acreditado na força do Integralismo e suposto que a união dos integralistas com a fascistizada colônia italiana ia garantir uma vasta influência italiana no país:

"Ele acreditava que o movimento brasileiro das assim chamadas "camisas verdes" era um movimento nitidamente fascista, o qual levaria ao poder um presidente, Getúlio Vargas, que faria do Brasil um grande Estado totalitário na democrática América Latina. As “camisas verdes”, os italianos e os alemães, numerosos e bem organizados no Brasil, subtrairiam o país da influência norteamericana e o aproximariam definitivamente ao Eixo" ${ }^{44}$.

Essa esperança de Mussolini logo se revelou vã. Apesar dos esforços do governo italiano para conservar as boas relações com o regime de Vargas e manter o Brasil, ao menos, neutro na guerra continuarem até $1941^{45}$, as considerações geopolíticas predominaram sobre a simpatia ideológica que o Estado Novo certamente mantinha pela Itália fascista e lentamente conduziram o Brasil para o campo aliado ${ }^{46}$.

Não é impossível, aliás, que o governo italiano tenha inferido o caminho pró-Estados Unidos seguido pelo governo brasileiro entre o final da década de 30 e o início da de 40 e tenha decidido, então, criar uma rede de espionagem no país para o caso de o Brasil efetivamente optar pelo campo aliado.

Na realidade, ao contrário da rede de espionagem alemã no Brasil do período, que foi realmente consistente e sobre a qual sabemos alguma coisa ${ }^{47}$, as informações sobre essa possível rede de espionagem italiana são fragmentárias e inconclusivas e não se sabe realmente muito sobre a mesma. 
Para o governo brasileiro, não havia dúvidas de que havia espionagem italiana no país, inclusive com uma seção da polícia política italiana, a OVRA, no Rio de Janeiro ${ }^{48}$. O governo inglês também acreditava na existência dessa rede, que teria surgido no início dos anos $40^{49}$ e os americanos chegavam a fornecer alguns detalhes da mesma, como, por exemplo, o núcleo de Natal/RN, destinado a vigiar as bases americanas no Nordeste brasileiro ${ }^{50}$. Há um consenso geral , porém, que era um sistema de espionagem imensamente inferior ao montado pelos alemães. ${ }^{51}$

Notícias sobre prisões de italianos (na maioria das vezes, ligados a empresas italianas como bancos ${ }^{52}$ ou a $\operatorname{LATI}^{53}$ e ao corpo diplomático italiano ou ainda aos órgãos fascistizados - como os fasci all'estero e os Dopolavoro das coletividades italianas espalhadas pelo país) são uma constante em 1942 e $1943^{54}$, com a maioria deles sendo processada pelo Tribunal de Segurança Nacional e libertada em 1944.

Dentre esses presos, alguns mereceram atenção especial da polícia brasileira, como Pietro Perosino ${ }^{55}$; os comandantes Coppola e Di Vicino, acusados de serem líderes da espionagem italiana no Rio de Janeiro e de desviarem fundos da LATI para financiar tais ações ${ }^{56}$; o diretor do Dopolavoro de São Paulo e suposto agente de ligação entre as máquinas de espionagem alemã e italiana Franco Cecchini ${ }^{57}$; o conde Edmondo di Robillant, que seria responsável pelo fornecimento a Roma das informações sobre partidas de navios mercantes do porto do Rio de Janeiro através de uma rádio clandestina montada em Jacarepaguá58; o veterano da Abissínia e membro do fascio do Rio de Janeiro Felippo Peviani (preso em 1941) ${ }^{59}$ e outros.

Sem dúvida, essa suposta atividade de espionagem por parte dos italianos era inflada pelo clima de guerra da época e é curioso não termos encontrado, na documentação diplomática italiana, uma confirmação formal de sua existência e alcance. De qualquer forma, há indícios suficientes para concluir que algum tipo de atividade desse tipo existiu ${ }^{60}$, o que é revelador sobre a qualidade do relacionamento ítalo-brasileiro nesse início dos anos 40.

De fato, a aposta italiana que a presença de uma imensa massa de italianos e descendentes no Brasil e que a solidariedade ideológica com o Integralismo e depois com o Estado Novo iam compensar suas deficiências econômicas e militares e gerar uma ampla influência italiana no país falhou totalmente, com a guerra encerrando melancolicamente uma fase de grandes expectativas da Itália em relação ao Brasil ${ }^{61}$.

A análise da ação fascista dirigida ao Brasil e à América Latina como um todo nos permite perceber, assim, como esta seguiu, com bastante coerência, as alterações no padrão da política externa italiana imprimidas por Mussolini e seu regime no decorrer do ventênio fascista. De fato, ela parte de uma visão de um Império cultural e econômico italiano a ser criado na região através dos 
emigrantes nos anos 20 para a idéia de criar uma zona de influência italiana baseada na solidariedade ideológica nos anos 30, o que reflete o crescimento das idéias imperialistas e totalitárias e a crescente importância do componente ideológico dentro da política externa italiana durante o período.

Essa política era muito cautelosa e pragmática e sua adaptação aos diferentes contextos representados pelos vários países da América do Sul é notável ${ }^{62}$ e seria conveniente a existência de mais estudos de caso para determinar com mais segurança os padrões de atuação fascista na América Latina.

Ela era também, sem dúvida, ambiciosa e com incoerências e improvisações evidentes. Ela nunca foi, porém, completamente aleatória e ilógica e, em última instância, revelou-se de efeitos importantes na vida política da América Latina, e do Brasil em particular, ao contribuir para a difusão e implementação dos ideais totalitários na região. De fato, o estudo dos interesses italianos no Brasil e de seus instrumentos de ação nos permite verificar melhor tanto os mecanismos de aprofundamento dos ideais fascistas na sociedade brasileira do entreguerras quanto o papel das potências fascistas e seus interesses no processo, o que é uma tarefa fundamental.

Agosto de 1997

\section{Bibliografia}

ALBONICO, Aldo. "Immagine e destino delle comunità italiane in America Latina attraverso la stampa fascista degli anni 30”. in Studi Emigrazione, XIX, 65:41-52, 1982.

ARALDI, Vinicio. Il Brasile sotto la presidenza Getulio Vargas. Rio de Janeiro: 1937.

BERTONHA, João Fábio. "Contra o fascismo e contra Mussolini: as estratégias dos socialistas italianos de São Paulo na luta contra o fascismo, 1923-1934” in Textos de História, Brasília: volume 4, número 1: 39-73, 1996.

BESSIS, Juliette. La Mediterranée fasciste - L'Italie mussolinienne et la Tunisie. Paris: Khartala, sem data.

BONACCI, Giovanni. L'Italia vitoriosa e la sua espansione nel mondo. Roma: Banca Italiana di Sconto, 1920.

BORSA, Giorgio. “Tentativi di penetrazioni dell’Italia fascista in Cina: 1932-1937". in Il Politico. XLIV, 3: 381-419, 1979.

CAMERA Italiana di Comercio ed arti di San Paolo del Brasile. Relazione presentata alla Crociera della R. Nave “Italia”. São Paulo: Rossetti \& Rocco, 1924.

CAMERA Italiana di Comercio ed arti di San Paolo del Brasile. Relazione presentata al Congresso Internazionale del Comercio in Rio. São Paulo: Typografia Paulista, 1927.

CANNISTRARO, Philip. Historical Dictionary of fascist Italy. Westport/London: Greenwood Press, 1982.

CANTALUPO, Roberto. Brasile Euro-americano. Milano: ISPI, 1941.

CARRAZONI, Andrè. Getulio Vargas. Padova: CEDAM, 1941.

CASSELS, Alan. Italian Foreign Policy, 1918-1945 - A Guide to Research Materials. Welmington: Scholarly Resources, 1991. 
CERVO, Amado Luís. As relações históricas entre o Brasil e a Itália - O papel da diplomacia. São Paulo/Brasília: Instituto Italiano de Cultura/Editora da UnB, 1992.

- História da politica exterior do Brasil. São Paulo: Ática, 1992a.

CICCARELLI, Orazio. "Fascism and Politics in Peru during the Benavides Regime, 1933-39” in Hispanic American Historical Review, v. 70, n. 3:405-432, ago/1990.

CLEMENTI, O. "La storia del fascismo in 870 titoli” in Quazza, Guido. Storiografia e fascismo. Milano: Franco Angeli, 1985, 119-152.

COGGIOLA, Osvaldo. Segunda Guerra Mundial. Um balanço histórico. São Paulo: FFLCH/USP, 1995.

DE FELICE, Renzo. Il fascismo e l'Oriente. Arabi, ebrei e indiani nella politica di Mussolini. Bologna: Il Mulino, 1988.

. Bibliografia Orientativa del fascismo. Roma: Bonacci, 1991.

DI NOLFO, Ennio. “Storia delle relazioni internazionali” in Bonaparte, Luigi. Studi Internazionali. Torino: Fondazione Giovanni Agnelli, 1990, 280-354.

. "Le oscillazioni di Mussolini” in Nuova Antologia, V. 564, f. 246: 172-195, out/dez 1990a.

DIFFIE, Bailey. “Some foreign influences in Contemporary Brazilian Politics” in Hispanic American Historical Review, XX, 3: 402-429, ag/1940.

DUCCI, Gino. Orientamento politico militari degli Stati Americani. Roma: 1938.

FERRETTI, Valdo. “La politica estera giapponese e i rapporti con l'Italia (1936-1939)” in Storia Contemporanea, VI, 4: 783-824, 1976.

- "La politica estera italiana e il Giappone imperiale (gennaio 1934 - giugno 1937)" in Storia Contemporanea, X, 4/5: 873-923, 1979.

. "Il patto cino sovietico del 21/8/38 e i suoi riflessi nella politica estera italiana" in Storia e Politica, 2, 1979a. 1983.

FERRI, Vincenzo. L'Italia nel Brasile di domani. Milano: La Stampa Commerciale, 1924.

GAMBINI, Roberto. O duplo jogo de Getúlio Vargas: influência americana e alemã no Estado Novo. São Paulo: Símbolo, 1977.

GIURIATI, Giovanni. La Crociera italiana nell'America Latina. Roma: Istituto Coloniale, 1925.

GODLEY, Michael. "Fascismo e nazionalismo cinese, 1931-1938. Note preliminari allo studio dei rapporti italo cinesi durante il periodo fascista” in Storia Contemporanea, IV, 4: 739-777, 1973.

GRANGE, D. “Structure et techniques d'une propagande: les emissions arabes de Radio Bari” in Relations Internationales, 2: 165-185, 1974.

\section{6.}

GUARIGLIA, Raffaele. Ricordi 1922-1946. Napoli Edizioni Scientifiche Italiane, 1950.

GUERRINI, Irene e PLUVIANO, Marco. “L'organizzazione del tempo libero nelle comunità italiane in America Latina” in Blengino, Vanni (org). La riscoperta delle Americhe. Lavoratori e sindacato nell'emigrazione italiana in America Latina, 1870-1970. Milano: Nicola Teti Editore, 1994, 378-389.

HARRIS, Bruce. The USA and the Italo-Ethiopian crisis. Stanford: 1964.

HILTON, Stanley. Suástica sobre o Brasil - A história da Espionagem alemã no Brasil. Rio de Janeiro: Civilização Brasileira, 1977.

- A guerra secreta de Hitler no Brasil. Rio de Janeiro: Nova Fronteira, 1983.

IMPERATORI, Ugo. Italia prodiga - Gli italiani all'estero. Milano: Alpes, 1924.

- Italia Madre - Gente Nostra per il mondo. Roma: Sapientia, 1929.

Gli ITALIANI nel Brasile. São Paulo: 1924. 
LALLI, Mario Tedeschini. “La propaganda araba del fascismo e l'Egitto” in Storia Contemporanea, VI, 4, 1976.

LEONINI, Camilo. L'emigrazione italiana nell'America Latina. Roma: Selecta, 1926.

LEVINE, Robert. O regime de Vargas - Os anos críticos, 1934-1938. Rio de Janeiro: Nova Fronteira, 1980.

LUMINARI, Laura. “Armi all’Irak: obiettivi e mezzi della politica fascista in Medio Oriente (1931-1941)’ in Storia Contemporanea, XXVI, 4: 537-571, 1995.

MACOLA, Ferruciio. L'Europa alla conquista dell'America Latina. Venezia: Ongania, 1894.

MANCINI, T. Problemi e mezzi della nostra penetrazione economica nell'America latina. Santiago del Chile: 1924.

MCDONALD, C. "Radio Bari and Italian propaganda in Middle East and British counter measures” in Middle East Studies, 2, 1977.

MORTARI, Giuseppe. Espansione Coloniale. Firenze: Ramella, 1904.

MICHAELIS, Meir. "I rapporti tra fascismo e nazismo prima dell'avvento di Hitler al potere (1922-1933)” in Rivista Storica Italiana, LXXXV, 3: 544-600, set/1973.

MOVIMENTI fascisti esteri. Roma: Ministero degli Affari Esteri, 1935.

MUGNAINI, Marco. "L'Italia e l’America Latina (1930-1936): alcuni aspetti della politica estera fascista” in Storia delle relazione internazionali, II, 2: 199-144, 1986.

NEWTON, Ronald. The Nazi Menace in Argentina, 1931-1934. Stanford: Stanford University Press, 1992.

NORMAN, John. "The influence of the pro fascist propaganda on american neutrality, 19351936” in Lee, Dwight e McReynolds, G. Essays in History and International Relations. Worchester: 1949, 193-214.

ORANO, Paolo. Espansione Coloniale. Roma: Pinciana, 1937.

OSTUNI, Maria Rosaria. “Una piú grande Italia? Istituzioni, coperture ideologiche ed emigrazione italiana in Brasile (1901-1927)” in Franzina, Emílio. Un altro Veneto - Saggi e studi di storia dell'emigrazione nei secoli XIX e XX. Albano Termi: Francisci Editore, 1983, 285319.

PASTORELLI, Pietro. "La storiografia italiana del dopoguerra sulla politica estera fascista” in Storia e Politica, X, 4: 575-614, out/dez 1971.

PEDRAZZO, Priscila. O perigo alemão e os mecanismos de repressão do Estado Novo. Dissertação de Mestrado. São Paulo: USP, 1997.

PERFETTI, Francesco. “L’Italia tra le due guerre” in De Felice, Renzo. Storia dell'Italia Contemporanea. Napoli: ESI, 1977, vol. IV.

PEVIANI, Filippo. L'attuale problema italo-brasiliano. Roma: SASI, 1922.

PETTINATI, Francesco. Il contributo degli italiani alla formazione del Brasile. Roma: 1941.

QUARATO, Raffaele. "La politica estera fascista nei scritti di Renzo de Felice” in Analisi storica, V, 8: 101-127, 1987.

QUARTARARO, Rosaria. “L'Italia e lo Yemen. Uno studio sulla politica di espansione italiana nel Mar Rosso” in Storia Contemporanea, X, 4/5: 811-871, 1979.

ROCCA, Enrico. Avventura sudamericana. Milano: Alpes, 1936 (1925).

SALA, Umberto. L'emigrazione italiana in Brasile, relatório ao Ministero degli Affari Esteri, 1925. Exemplar datilografado.

SANTARELLI, Enzo. Storia del fascismo. Roma: Riuniti, 1981.

SCHRODER, J. “I rapporti tra le potenze dell'Asse e il mondo arabo” in Storia Contemporanea, II, $1,1971$.

SEIFERHELD, Alfredo. Nazismo y fascismo en el Paraguay. Visperas de la II Guerra Mondial, 1936-1939. Assunciòn: 1985.

Assunción: 1986.

. Nazismo y fascismo en el Paraguay. Los anos de la guerra, 1939-1945. 
SEITENFUS, Ricardo. “Ideology and Diplomacy: Italian Fascism and Brazil (1935-1938)” in Hispanic American Historical Review, 64/3: 503-534, 1984.

. O Brasil de Getúlio Vargas e a formação dos blocos 1930-1942 (O processo de envolvimento brasileiro na II Guerra Mundial). São Paulo: Cia Editora Nacional, 1985.

. “As relações entre Brasil e Itália no período 1918-1939” in DE BONI, Luís Antonio. A presença italiana no Brasil, vol. 2. Porto Alegre/Torino: EST/Fondazione Giovanni Agnelli, 1990, 37-52.

STRIKA, Vincenzo. "Il mancato viaggio di re Faysal in Italia. I rapporti italo irakeni (1929-1933)" in Storia Contemporanea, XV, 3: 371-398, 1984.

SURDICH, Francesco. "Il Problema dell'emigrazione in un giornale di armatori genovesi: "L'Italia all'estero (1884)” in Porto e Aeroporto di Genova, LXXIV, 10: 961-968, out/1980.

. "L’emigrazione di massa e la Società Geografica Italiana” in Franzina, Emílio. Un altro Veneto - Saggi e studi di storia dell'emigrazione nei secoli XIX e XX. Abano Terme: Francisci, 1983, 234-256.

TOSCANO, Mario. "Il fascismo e l'Estado Novo” in De Felice, Renzo. L'emigrazione italiana in Brasile, 1800-1978. Torino: Fondazione Giovanni Agnelli, 1980, 235-270.

TRENTO, Ângelo. "Relações entre fascismo e Integralismo: o ponto de vista do Ministério dos Negócios estrangeiros italiano” in Ciência e Cultura, XXXIV, 12: 1601-1613, 1982.

Paulo: Nobel, 1989.

VENTRESCO, Fiorello. "Italian Americans and the Ethiopian crisis” in Italian Americana , VI, 1: 4-28, out/dez 1980.

VILLA, Oreste. L'America Latina - Problema fascista. Roma: Nuova Europa, 1933.

VILLARI, Luigi. Le agressioni degli Stati Uniti nell'America Latina. Roma: Carlo Colombo, 1941. ZOLI, Corrado. Sud America. Roma: SIAG, 1927.

\section{Notas}

1 Para informações bibliográficas sobre a política externa fascista, vide PASTORELLI (1971); PERFETTI (1979); CLEMENTI (1985, p. 119-152) e, especialmente, DI NOLFO (1990); CASSELS (1991) e DE FELICE (1991).

2 Sobre os países árabes e o Oriente Médio, vide SCHRODER (1971); GRANGE (1974 e 1976); LALLI (1976); MCDONALD (1977); QUARTARARO (1979); STRIKA (1984); DE FELICE (1988) e LUMINARI (1995). Para a China, ver GODLEY (1973); BORSA (1979) e FERRETTI (1979a), enquanto, para o caso japonês, são úteis os textos de FERRETTI (1976, 1979 e 1983).

3 Vide SEITENFUS (1990, p. 37). As informações biográficas levantadas por Philip Cannistraro (CANNISTRARO, 1982) sobre os membros do corpo diplomático e do Partido fascista que serviram no Brasil no entreguerras - a maioria do primeiro time dentro da estrutura diplomática italiana - também mostram como o Brasil não era um lugar tão marginal assim. Vide os verbetes sobre Bernardo Attolico, Roberto Cantalupo, Luigi Freddi, Vincenzo Lojacono e outros.

4 Quando não houver menção em contrário, as informações a seguir se originam de CERVO (1992).

5 Vide MACOLA (1894); MORTARI (1904) e UBALDI (1911). Na realidade, a idéia de algum tipo de relacionamento colonial (normalmente mediada pelo instrumento não militar representado pela emigração italiana no sub-continente) da Itália com a América Latina nesse período visava especialmente a Argentina, mas o sul/sudeste do Brasil nunca foi ignorado. 
Sobre essa preferência pelo Brasil em alguns grupos intelectuais italianos, vide SURDICH (1980 e 1983).

Para o “perigo alemão”, que gerou grandes apreensões no Brasil no século XIX e primeira metade do XX, vide uma lúcida análise em GERTZ (1987, cap. 2 e 1991) e uma bibliografia alemã atualizada sobre o assunto em GERTZ (1995). Sobre o perigo japonês, que causava apreensões, mas menores que as suscitadas pelos alemães, algum material está disponível nos arquivos do DOPS de São Paulo e do Rio de Janeiro, mas falta ainda um bom livro sobre as atividades japonesas no Brasil do período. Existem também vagas indicações sobre uma ameaça imperialista polonesa, com a utilização da enorme colônia polaca presente no Paraná, a qual era obviamente absurda, mas reflete o "clima” frente às coletividades estrangeiras no Brasil do período. Sobre a ameaça polonesa, ver AN?MJNI 1932-1939, IJ1 1319 e Caixa 75, p. 904. Ver também LEVINE (1980, pp. 62-63).

7 Ver RIOS (1959, p. 41). Para artigos da imprensa brasileira discutindo a possível existência de um “perigo italiano”, vide Arquivo Histórico do Itamaraty (AHI), 26/3/23, Notas da Embaixada italiana para o Itamaraty, ofício de 7/2/1924. A mesma série documental, no seu ano de 1932 (85/4/5), apresenta diversos despachos da Embaixada italiana dando conta de um curioso sentimento anti-italiano em Minas Gerais, Rio de Janeiro, etc, onde o "perigo italiano" era associado à rebelião dos paulistas. Sinais que, se a idéia do "perigo italiano" jamais foi realmente levada tão a sério como o alemão, não deixou de existir.

8 Para informações sobre como ao menos parte da opinião pública italiana via realmente o Brasil como a única possibilidade real de alívio demográfico italiano e sobre como esse ideal era perturbado pelas contínuas notícias sobre maus tratos aos italianos no Brasil, vide AHI, 229/3/7, Ofícios da Embaixada Brasileira em Roma, diversos ofícios de 1922 e 1923. Ver também AHI, 273/2/4, p. "Conferência internacional de emigração e imigração (1924)”, relatório reservado de Afonso Bandeira de Mello, 18/12/1924.

9 Ver ITALIANI (1924, p. 7-13) e detalhes em “Atti Ufficiali” in Bollettino della Camera Italiana di Commercio di San Paolo, XXI, 178, jan/jun 1924

10 A missão Giuriati à América Latina em 1924 era baseada num grande cruzeiro do navio "Italia” a inúmeros portos latino-americanos para apresentar e vender produtos italianos. Sobre ela, ver CERVO (1992, p. 98-99); GIURIATI (1925) e AHI, 229/3/8, Ofícios da Embaixada brasileira em Roma de julho 1923 a dezembro 1924. Ver também as edições do Bollettino della Camera Italiana di Commercio di San Paolo de 1924.

11 Vide as declarações do embaixador Badoglio em 1924 sobre a necessidade de enviar não só os braços mas também a inteligência italiana ao Brasil e de Giovanni Giuriati sobre a "obra de expansão italiana na América Latina” em ITALIANI (1924, p. 8-14).

12 Vide BONACCI (1920); PEVIANI (1922); FERRI (1924); IMPERATORI (1924 e 1929); ROCCA (1925) ; LEONINI (1926) e ZOLI (1927). Ver também as revistas Rivista d'Italia e d'America e Colombo, surgidas nesse período justamente para dinamizar o relacionamento cultural com a América Latina e especialmente “L'utilità di una spedizione in Brasile” in Rivista d'Italia e d'America, IV, 12, dez/1926 sobre a complementariedade entre as economias brasileira e italiana.

13 Já em 1920, por exemplo, Mussolini, num discurso em Trieste, se referiu ao Estado de São Paulo como um lugar onde logo a língua e a cultura dominantes seriam, dada a predominância numérica, italianas. Vide ORANO (1937, p. 21).

14 Vide SALA (1925). Exemplar datilografado pertencente à Biblioteca do Ministero degli Affari Esteri/Roma.

15 De fato, as relações econômicas e a penetração cultural dos italianos no Brasil não tiveram, como esperava Roma, grande avanço nos anos 20 devido à escassa disponibilidade de capitais italianos e sua fraqueza industrial, à influência americana e à pouca disponibilidade da 
coletividade italiana em obedecer incondicionalmente as diretrizes de Roma. Vide TOSCANO (1980); CERVO (1992) e TRENTO (1989).

16 O número de missões militares italianas na América Latina, por exemplo, parte de zero em 1935 para 10 em 1938. Vide Archivio Storico Ministero degli Affari Esteri (ASMAE)/Affari Politici 1931-1945 (Brasile), b. 29, p. “Miscellanea”, 1944

Idem, b. 1, p. "Rivoluzione in Brasile - Governo provisorio”, Pro memoria MAE de 1931.

18 Idem, b. 4, p. "Rapporti politici”, Relatório Embaixada do Rio de Janeiro, 11/4/1933.

19 Como, aliás, os próprios italianos estavam conscientes. Ver ASMAE/Affari Politici 19311945 (Brasile), b. 11, f. 9, Relatório Embaixada italiana, 20/3/1937.

20 Vide DI NOLFO (1990a, p. 183) para uma discussão sobre como o crescimento das ambições imperiais fascistas nos anos 30 e especialmente no pós 1936 e a visão de Mussolini que a luta imperialista nesse momento teria que ser travada em escala global levaram o regime a se envolver em áreas antes consideradas periféricas, como a América Latina, o Extremo Oriente, etc.

21 Houve também uma certa preocupação com a atividade dos japoneses no país e até com a dos poloneses, o que revela o "clima” com relação aos estrangeiros naqueles anos.

Sobre as atividades polonesas, ver AN/MJNI - Arquivo Nacional/Ministério da Juestiça e dos Negócios Interiores, 1933-1939, Ij1 1319 e Caixa 75, p. 904. Ver também LEVINE (1980, pp. 62-63).

22 Um caso foi um boato de 1938 que dizia que um golpe de estado nazista/integralista ia instalar um protetorado nazista nos estados do Sul do Brasil, enquanto o Estado de São Paulo seria entregue à Itália fascista. Vide DIFFIE (1940, p. 426). Ainda em 1938, circulou outro boato descrevendo o complô das potências fascistas com a Argentina, que queriam conquistar o Paraguai e a Bolívia e desmembrar o Brasil, que seria dividido entre a Alemanha (Rio Grande do Sul/Santa Catarina, o sul do Paraná e parte do Mato Grosso), a Itália (Norte do Paraná, parte de Mato Grosso e São Paulo) e o Japão (a Amazônia). Vide Fundação Getúlio Vargas/CPDOC, Arquivo Osvaldo Aranha, rolo 15, fotograma 617, relatório "Interesses estrangeiros pelas nossas terras - política argentina)”, 1938.

23 Vide SANTARELLI (1981, p. 116-118) e ASMAE/Affari Politici 1931-1945 (Brasile), b. 15, p. “Integralismo - Rifugiati Politici”, relatório Embaixada italiana, 18/3/1937. e b. 16, p. “Situazione Politica interna - 1938”, carta de Eugenio Coselschi à Ciano, 13/11/1937. Coselschi, aliás, era o chefe dos Comitati per l'universalità di Roma, embrião de uma Internacional fascista.

24 Ver uma prematura análise nesse sentido em VILLA (1933) e uma carta de Mário da Silva ao Ministero della Cultura Popolare (MinCulPop) de 20/12/1937, onde tal idéia é abertamente defendida em TOSCANO (1980, p. 247) .

25 ASMAE/Affari Politici 1931-1945 (Brasile), b. 11, f. 9, p. "Situazione Politica in Brasile 1937”, Telespresso MAE, sem data.

26 ASMAE/Affari Politici 1931-1945 (Brasile), b. 11,, f. 1, memorando reservado ao Embaixador Lojacono, 26/4/1937.

27 Nesse aspecto, a situação difere radicalmente da dos Estados Unidos onde a estrutura política era mais permeável à influência dos italianos e onde a atividade deles foi chave para determinar a neutralidade americana frente à Guerra da Abissínia. Ver VENTRESCO (1980); HARRIS (1969) e NORMAN (1949).

28 Ver também o longo relatório da Embaixada italiana citado na nota 18.

29 ASMAE/Affari Politici 1931-1945 (Brasile), b. 11, f. 1, memorando reservado ao Embaixador Lojacono, 26/4/1937.

30 ASMAE/Affari Politici 1931-1945 (Brasile), b. 6, p. "Brasile- Rapporti Politici”- 1934", Informe Embaixada italiana, 4/8/1934.

31 ASMAE/Affari Politici 1931-1945 (Brasile), b. 15, p. "Integralismo - Rifugiati Politici”, relatório do Dr. Colpi à Embaixada italiana, 12/8/1938. 
Vide, a propósito, a discussão mantida pelos órgãos diplomáticos italianos no Brasil em 1939 sobre como a maioria dos descendentes de italianos não eram mais “recuperáveis” para a Itália e que a única solução possível seria a transferência dos que ainda se sentiam italianos para a África Oriental e sobre como qualquer influência da Itália sobre os descendentes de italianos no Brasil só poderia ser obtida se Roma se adaptasse a dura realidade da assimilação e usasse as armas adequadas como, por exemplo, um jornal em português.

Essas discussões estão em ASMAE/Affari Politici 1931-1945 (Brasile), b. 24, p. "Rapporti Politici 1940”, vários documentos e Archivio Centrale dello Stato/Ministero della Cultura Popolare, Divisione Generale di Propaganda, b. 278, f. 14, sottof. 1, p. "Brasile - Propaganda italiana”. Carta Cesco Tomaselli à Alessandro Pavolini, 4/12/1939.

Vide TRENTO (1982); SEITENFUS (1984, 1985 e 1990) e CERVO (1992) para informações sobre o subsídio financeiro da Itália fascista aos integralistas e outros aspectos de interesse. René Gertz vai nos informar (GERTZ, 1987, p. 118-138) que não só as relações entre o governo nazista e os integralistas foram muito mais conflituosas que aquelas entre o Integralismo e o fascismo italiano, como a Alemanha confiou muito menos que a Itália na solidariedade ideológica com a Ação Integralista para defender seus interesses no Brasil. Tal situação derivava, possivelmente, do fato da Itália fascista se utilizar muito mais dos ideais da "Internacional fascista" para proteger seus interesses que a Alemanha nazista. Vide MICHAELIS (1973).

35 ASMAE/Affari Politici 1931-1945 (Brasile), b. 15, relatório reservado de 27/9/1937, citado em SEITENFUS (1990, p. 51).

36 Arquivo do Estado de São Paulo/Delegacia de Ordem Política e Social (AESP/DOPS), Prontuário 613 (“César Rivelli”), relatório ao Consulado italiano de 20/5/1938 (apreendido pela polícia). O mesmo documento está em Arquivo Nacional/Ministério da Justiça e dos Negócios Interiores, 1933-1939 (AN/MJNI), Caixa 392, pasta 1031/38, "Processo de Expulsão de César Rivelli”. Ver também o curioso livro de Gino Ducci (DUCCI, 1938), onde ele questiona o “egoísmo” americano em querer o domínio exclusivo da América Latina.

Outro documento curioso é uma carta do diretor dos Comitati per l'universalità di Roma (CAUR), Eugenio Coselschi, ao Conde Ciano, onde ele propõe enviar Emílio Santi ao Brasil para examinar a situação local em vista dos objetivos de intervir na Ação Integralista para equilibrar a influência nazista e controlar Salgado para conduzí-lo à criação de um bloco econômico latino-americano ligado à Roma. Ver ASMAE/Affari Politici 1931-1945 (Brasile), b. 16, p. “Situazione politica interna - 1938”, carta de Eugenio Coselschi à Ciano, 13/11/1937. Vide SEITENFUS (1990, p. 50). Ver também vários despachos da Embaixada italiana de março a abril de 1938 onde a dúvida sobre a melhor opção para os interesses italianos no Brasil é manifesta. Ver ASMAE/Affari Politici 1931-1945 (Brasile), b. 16, p. "Situazione politica interna - 1938”.

38 Idem

39 ASMAE/Affari Politici 1946-1950 (Brasile), b. 1, p. “Stampa in Brasile, 1946”.

40 Arquivo Diplomático Americano (ADA), Rolo 3/380, código 832,00, fotograma 1114, Memorando da Embaixada americana em Roma ao Departamento de Estado, 18/11/1937.

41 Para exemplo dos enormes elogios que a propaganda italiana faz ao regime de Vargas e ao próprio desde 1937 até 1941, vide CANTALUPO (1941); ARALDI (1937); CARRAZONI, (1941) e a imprensa fascista editada no Brasil naquele momento. Ver também Valentini, Giuseppe. “10 Novembre” in Littoria, II, 14, nov/1938, onde o autor, assessor de imprensa da Embaixada italiana no Rio de Janeiro, compara o Estado Novo com o fascismo e Vargas com Mussolini. Para análises posteriores, ver TOSCANO (1980) e SEITENFUS (1990). A idéia de que a chamada “diplomacia paralela” (de apoio ao Integralismo) fosse, de fato, cem por cento separada das estruturas do Estado italiano e do partido fascista instaladas entre as 
comunidades italianas no Brasil - como quer GUERRINI (1994, p. 388-389) merece, realmente, ser relativizada.

43 ASMAE/Affari Politici 1931-1945 (Brasile), b. 11,, f. 9, 1, memorando do MAE ao Embaixador Lojacono, 3/5/1937.

44 GUARIGLIA (1950, p. 334).

45 Ver CANTALUPO (1941); CARRAZONI, (1941); VILLARI (1941) e PETTINATTI (1941). Uma informação interessante é que, aparentemente, setores do governo fascista chegaram a pensar em fazer um retorno à carta integralista quando se confirmou a “traição” de Vargas. Vide os contatos do governo fascista com Plínio Salgado (então exilado em Portugal) em ASMAE/Affari Politici 1931-1945 (Brasile), b. 11 e uma curiosa carta de F. Pietro à Vincenzo Coppola (agente do governo italiano no Brasil) de 30/10/1941, onde ele comunica que, dada a aproximação de Vargas com os americanos, a única solução que Roma conseguia vislumbrar era apoiar novamente "nossos amigos camisas verdes”. Vide o original da carta em Arquivo do Estado do Rio de Janeiro/Arquivo Dops (AERJ/DOPS), Série Temática “Espionagem”, Pasta 3, Dossiê "LATI".

46 Vide SEITENFUS (1985); COGGIOLA (1995) e GAMBINI (1977).

47 Vide HILTON (1977 e 1983). Ver também PERAZZO (1997) e NEWTON (1992).

48 Vide AERJ/DOPS, Série Temática “Italianos”, Pasta 3, Dossiês “OVRA” e "Empresa Editorial Vecchi” e Série Temática “Espionagem”, Pasta 3, Dossiê “Espionagem na Argentina”.

49 Public Records Office/Foreign Office, PRO, FO 128/390, relatório "German Activities in Pernambuco” e FO 128/393, relatório do Consulado de São Paulo, 18/1/1941, anexo 1 “The Fascist organization in the state of San Paulo".

50 Ver informações diversas sobre esse possível núcleo de espiões italianos em NACP -National Archives at College Park/General Records of the Department of State, RG 59, 250/30/9/6 Box 5659, 865.20210, pastas. “Latorraca, Heitor”; “Leoni, Manlio” e “Lettieri, Guglielmo” e em NACP/General Records of Latin American Branch, RG 165, 390/35/17-18/5 - 1, Entry 188, Box 976, p. “Argentina - Italians”, relatório do FBI de 30/4/1945. Esse último relatório confirma, aliás, que a estrutura de espionagem italiana visava basicamente o Rio de Janeiro e Natal (informações sobre o tráfego naval) e que, após a entrada do Brasil na guerra, era coordenada através de Buenos Aires.

51 Ver ASMAE/Affari Politici 1931-1945 (Brasile), b. 27, p. "Protezione interessi italiani in Brasule”, Informe Embaixada de Lisboa, 12/5/1942.

52 Ver NACP/General Records of the Department of State, RG 59, 250/30/9/6 Box 6877, 862.20211/1895, relatório de 21/12/1938 e Box 5655, cartas do Consulado americano de Marselha de 28/5 e 7/8/1941, que identificam empregados dos Bancos da Sicília e di Napoli de São Paulo como agentes fascistas.

53 Vide AERJ/DOPS, Série Temática “Espionagem”, Pasta 3, Dossiê “LATI”. Às empresas aéreas alemã (Condor) e, especialmente, italiana (LATI) era atribuído, aliás, papel chave na espionagem e contrabando para o Eixo pelos governos americano e inglês. Ver Foreign Relations of the United States - Diplomatic Papers, 1940, v. 5, pp. 658-669; 1941, v. 6, pp. 514-528 e 1942, v. 5, p. 766 e BURDEN (1942) para o imenso esforço americano para sobrepujar a LATI e a Condor na aviação regional e desmontar essa rede. Ver também HILTON (1994, pp. 368-372).

54 Vide AERJ/DOPS, Série Temática “Espionagem” , Pasta 2, Dossiê “Condenado por espionagem” e Pasta 3, Dossiê “LATI”. Ver também ASMAE/Affari Politici 1931-1945 (Brasile), b. 27 a 30. Vide AERJ/DOPS, Série Temática “Espionagem”, Pasta 3, Dossiê “Pietro Perosino”.

56 ASMAE/Affari Politici 1931-1945 (Brasile), b. 27, p. "Protezione Interessi italiani in Brasile - 1942”, Informe Embaixada de Buenos Aires, 22/9/1942 e AERJ/DOPS, Série Temática Espionagem, Pasta 2, Dossiê “Condenados por espionagem”. 
57 Vide ASMAE/Affari Politici 1931-1945 (Brasile), b. 27, p. "Protezione Interessi italiani in Brasile - 1942”, Telegrama Embaixada de Lisboa, 15/4/1942 e AERJ/DOPS, Série Estados/ São Paulo, Pacote 22B, Dossiê “Associação Opera Nazionale Dopolavoro”, Comunicado de 2/10/1942.

58 Vide AERJ/DOPS, Série Temática “Espionagem”, Pasta 4, Dossiê “Caso Edmondo di Robilart” e AERJ/Acervo DESPS, Notação 78, “Inquérito contra Edmondo di Robillant e outros”, 21/ 9/1942. Ver também ASMAE/Affari Politici 1931-1945 (Brasile), b. 27, p. "Protezione Interessi italiani in Brasile - 1942”, Telegrama da Embaixada de Lisboa, 23/9/1942.

59 Vide AERJ/DOPS, Série Temática "Espionagem”, Pasta 3, Dossiê "LATI"

60 Ainda que tenha sido muito inferior, como já observado, à espionagem nazista e sem uma coordenação completa com estes e com os japoneses, como temia o governo brasileiro na época.

Para um documento nesse sentido, que informa como o Japão era o encarregado da espionagem nos países da costa pacífica da América do Sul, a Alemanha do sul do Brasil e do continente e a Itália o resto do Brasil, incluindo São Paulo, vide AN/MJNI, 1933-1939, IJ1 1426, Ofício do Itamaraty ao Ministério da Justiça, 12/5/1942

61 Nada mais emblemático da decepção italiana que as palavras amargas do embaixador Raffaele Guariglia (GUARIGLIA, 1950, p. 333-334) se recordando como a presença maciça de italianos no Brasil não o impediu de fazer a guerra contra a Itália e o artigo do órgão oficial dos fasci all'estero Il Legionario, comentando a entrada do Brasil na guerra como uma traição de Getúlio Vargas e não do Brasil latino e fecundado pelos italianos. Vide “Questo Brasile” in Il Legionario, XIX, 15/16, 31/8/1942. Vide também AHI, 41/4/11, Ofícios da Embaixada brasileira em Roma ao Itamaraty, diversos ofícios de 1942, onde diversos jornais italianos comentam a "ingratidão brasileira”.

62 De fato, enquanto no Brasil a existência de um forte movimento fascista local levou o governo fascista a investir mais na propaganda e nas relações com esse movimento e o Estado Novo, a situação, por exemplo, no Peru era diversa, com a falta de um movimento fascista dinâmico como no Brasil levando Roma a apostar suas fichas mais na capacidade de influência dos italianos locais e na relação com o governo Benevides que no fascismo local. Vide CICCARELLI (1990).

Também na Argentina e no Paraguai a situação é diversa da brasileira, com os fascistas argentinos recebendo, possivelmente por estarem visivelmente longe da possibilidade de atingir o poder, pouca atenção de Roma, que também ignorava o Paraguai. Ver NEWTON (1992, p. 135) e SEIFERHELD (1985 e 1986). A política italiana se adaptava, pois, aos interesses estratégicos da Itália e à situação de cada país.

\section{Resumo}

O artigo busca delimitar os objetivos da Itália fascista no Brasil e fazer um balanço das relações entre os dois países no período entre as duas guerras. $\mathrm{O}$ argumento central gira em torno da política migratória italiana e da aproximação dos agentes e agências fascistas no Brasil aos imigrantes de origem italiana e seus descendentes. 
Abstract

The article intends to delimit the goals of fascist Italy in Brazil and make a balance of the relations among these countries during the period between World War I and II. The central argument is based on the analysis of Italian migratory policy and the approximation of fascist agents and agencies in Brazil and the Italian immigrants and their descendants.

Palavras-chave: Imigração italiana. Brasil. Fascismo. Política Externa. Key-words: Italian immigration. Brazil. Fascism. Foreign Policy. 